
architects deal with design-use complexities

\author{
Liesbeth Stam, Peter-Paul Verbeek, Ann Heylighen
}

\begin{abstract}
Design-use relations are complex: architects influence social outcomes through design without having control over them. Making this complexity explicit during design is important, but difficult. Promising is work on human-technology relations in science and technology studies (STS) and philosophy of technology. With an eye to connecting this theoretical work to design practice, we study what architects already do: how design-use complexities figure during design processes and how architects deal with them. Based on a case study of the design competition for a new media building, we show two lines of reasoning in architects' anticipation of use: specificity and openness. In doing so, we aim to provide insight into when, where and why they can benefit from STS and philosophical theory.
\end{abstract}

Keywords - architectural design, case study, design knowledge, design process, design-use relations 
Research highlights - how architects deal with design-use complexities:

- Anticipating use entails a continuous testing of solutions between specificity and openness.

- To foster particular social outcomes architects develop specificity into their designs.

- To deal with the unpredictability of use architects aim to create open designs. 


\title{
Between specificity and openness: How architects deal with design-use complexities
}

\begin{abstract}
Design-use relations are complex: architects influence social outcomes through design without having control over them. Making this complexity explicit during design is important, but difficult. Promising is work on human-technology relations in science and technology studies (STS) and philosophy of technology. With an eye to connecting this theoretical work to design practice, we study what architects already do: how design-use complexities figure during design processes and how architects deal with them. Based on a case study of the design competition for a new media building, we show two lines of reasoning in architects' anticipation of use: specificity and openness. In doing so, we aim to provide insight into when, where and why they can benefit from STS and philosophical theory.
\end{abstract}

Keywords - architectural design, case study, design knowledge, design process, design-use relations

Architecture and social life are deeply intertwined. Buildings and spaces do not simply or merely fulfil particular needs, they also affect social life in less obvious ways. Through their particular material lay-out buildings may influence how people's practices and experiences take shape. And they may do so in ways that are not always directly linked to their functions. Design is bound up in this: for the simple reason that buildings are designed objects. This means that architects through design influence social life.

It seems almost superfluous to say that it is important for architects to be alert to architecture's social effects. And not only to prevent negative outcomes. Understanding what architecture 'does' once built and in use, how it affects people's doing and being when it becomes part of their daily lives may help architects to create better buildings. Better in the sense of having a more desirable social effect - e.g., in terms of usability but also inclusivity or sustainability.

The idea that architects can deliberately influence the social context is widely acknowledged.

Particularly during the early $20^{\text {th }}$ century architects were often driven by strong social ambitions. But today still. Awan et al. (2011, p. 37) write: ' If you ask a potential architecture student why they want to study architecture, the most common response is: "I want to design buildings and make the world a better place". Conceptualizing architects' influence on the social context is, however, far less obvious. There is no clear-cut causal relation between architects' activities and the eventual social 
outcomes: design-use relations are very complex. These complexities involve issues of agency and control (Redström, 2008).

On the one hand architects always affect social dynamics: when designing a building as a physical object (in terms of form, material, ...), architects inherently inscribe assumptions about how it will be used, and thereby invite or constrain certain outcomes (cf. Akrich, 1992). On the other hand these outcomes can never be designed directly - they are deeply contingent (Till, 2009). They emerge in interactions between buildings and their users in specific contexts - contexts that change over time. These interactions can be seen as a 'process of tuning' in which people do not inescapably follow design intentions, but rather find desirable ways of living with their surroundings: they tune their practices as well as their surroundings to fit ever-changing contexts (cf. Alexander, 1966).

In architectural design processes these design-use complexities - i.e., issues of agency and control are rarely made explicit (Awan et al., 2011; Till, 2009; Brand, 1995). We write from the belief that, in order for architects to engage with the social cause, it is important to bring into view these complexities during design, that is to recognize the active role of users and to acknowledge architecture's contingency. Bringing into view these complexities is particularly important in architectural design, given that buildings often are used over a long period of time by a rich diversity of people.

A discourse is starting to take shape that brings attention to the complex interweaving of architecture and social life (see e.g., Gieryn, 2002; Till, 2008, 2009; Yaneva, 2009a; Fallan, 2011; Müller \& Reichmann, 2015; Stender, 2017) and what this means for understanding architecture practice (Awan et al., 2011; Brand, 1995; Hill, 2003; Yaneva, 2009b, 2012). This discourse often draws on insights from philosophical and social studies of technology, which bring a new epistemological orientation for understanding human-architecture relations. Work in science and technology studies (STS) and the philosophy of technology, despite different and often even competing views, commonly recognizes a mutual shaping relation between humans and technology. Mutual shaping refers to an ongoing interaction between humans and technological artefacts in which we, humans, through design and use shape technologies and technologies in turn shape us our practices, our experiences even our perceptions. ${ }^{1}$

This view of mutual shaping offers an alternative to two prevailing and opposing interpretations of human-technology relations that either prioritize the social (humans shape technology) or the

\footnotetext{
${ }^{1}$ A sampling of important work includes SCOT (social construction of technology) (Pinch \& Bijker, 1984), Akrich's (1992) description of technological artefacts, ANT (actor network theory) accounts of technology (Latour, 1992, 1994), work on user-technology relationships (Oudshoorn \& Pinch, 2005), Domestication theory by Silverstone and Haddon (1996), Pickering's (1995) 'mangle of practice' and idea of the 'dance of agency', Barad's (2003) work on 'intra-action' and the tradition of postphenomenology and associated theory of technological mediation (Ihde, 1990; Verbeek, 2005).
} 
technical (technology shapes humans). The former, sometimes referred to as the instrumental view, sees technologies as mere extensions of human agency; as neutral instruments that allow humans to do specific actions. The latter view, referred to as technological determinism, sees technologies as the cause of social change; as directly linked to positive or negative outcomes without any concern for human agency. Both views are not strange to architecture as we will discuss more thoroughly in the background section of this article. Extending them to design translates into design approaches that implicitly attribute full responsibility for social outcomes to either users (instrumentalism) or to designers (determinism). The idea of mutual shaping allows a more even distribution of responsibilities.

Therefore, beyond bringing an alternative epistemological orientation to understanding humanarchitecture relations, we believe that theories from STS and philosophy of technology may also more directly inform design practice and support architects in dealing with design-use complexities. Such theories include for example (elaborations of) social construction of technology (SCOT), actor network theory (ANT), script analysis, domestication theory and theory of technological mediation. Even though researchers have stressed the importance of this theoretical work to inform practice, few studies focus on actual implications for designing - i.e., how such theory can support architects 'in the act of designing'.

Important to note is that also among STS scholars and philosophers of technology there is increasing awareness of the potential of their theories to inform design processes, leading to a growing number of philosophical tools and methods of technology assessment to apply during design (Eggink \& Dorrestijn, 2018). These efforts however, we observe, rarely have attention for how such tools or methods may tie in with what designers already do - how they know and work. Yet, we believe that 'simply offering' designers such theoretical insights seems to be inadequate to truly connect with design practices, to become part of designers' design knowledge. Also, so far few, if any, studies in STS and the philosophy of technology have been geared towards architectural design practice specifically.

As a result, little progress has been made regarding how such STS/ philosophical theories can support architects during design in dealing with design-use complexities.

In relation to these developments, in this article we are interested not so much in specific theories or concepts coming from STS and/or the philosophy of technology and their applicability in architectural design practices, but rather in understanding how theoretical insights about humantechnology relations (in general) can tie in with architects' ways of knowing and working. When and where in design processes can architects benefit from this knowledge?

We argue that, in order to align such theoretical insights with design practice, it makes sense to study what it is that architects (already) do. Given that bringing together the material and social is fundamental to design - Gieryn (2002, p. 42) poses that "designers necessarily theorize about social life as much as sociologists do" - it would be strange to assume architects are not somehow (implicitly or explicitly) preoccupied with or aware of the complexities of relations between architecture and social life, and by extension between design and use. 
In order to identify opportunities for connecting this theoretical work and design practice, we are interested in how architects conceptualize human-architecture relations and deal with design-use complexities in practice. To be sure - in this article we will not elaborate specific philosophical or STS theories or concepts and how they may be taken up by architects in dealing with design-use complexities. This is rather the focus of ongoing research for which we consider this work a necessary stepping stone.

In this article we report on an explorative case study inquiry of the design competition for a new media building in Brussels. In-depth interviews with architects complemented with their firms' design entries and a documentary series about the competition gave insight into how these architects anticipated social outcomes of their media-building-in-design during the design process. When it comes to 'thinking use' during design, our analysis shows two lines of reasoning- specificity and openness: architects try to create a media building that is specific, such that it facilitates media production and consumption in specific ways; and that is open, such that it can grow with the fast changing world of media.

In the final section we discuss how our findings may give focus to future research into where particular theories can open up discussions and support reflections, during design, about what happens when people in all their diversity start using buildings and spaces in the multiplicity of everyday life.

\section{Background}

As noted in the introduction, the idea that social outcomes can or even should be a specific design concern is far from new. Particularly the early and middle decades of the $20^{\text {th }}$ century are marked by strong social engagement in architectural design. This engagement is exemplified by the many architecture programs and manifestoes stemming from this period. Several documents in Ulrich Conrads' (1975) reader 'Programs and Manifestoes on 20th -Century Architecture' stood at the beginning of important developments in modern architecture. Examples include the statements of Henry van Velde and Adolf Loos, Gropius' initial program for the famous Bauhaus, Le Corbusier's 'Toward a New Architecture' and proclamations of Theo van Doesburg and Ludwig Mies van der Rohe. Conrads' reader also includes collective statements issued in the name of movements such as De Stijl and CIAM (Congrès Internationaux d'Architecture Moderne). Many of these texts emphasize the intimate relationship between architecture and social life. They point out the societal responsibility of architects, whom should see it as their task and duty to employ their technological expertise to lead society into a better future.

Even though we know little about how modern architects imagined and thought about use during design, their writings suggest that they attributed themselves a significant - even determining - role in realizing particular outcomes. In his program for the Bauhaus Hannes Meyer (1928, p. 120), for example wrote: "building is the deliberate organization of the processes of life". Like Meyer's program, many of these famous texts imply a direct relation between architects' activities (design) and social outcomes of their designs (use). The complexities with which 'the processes of life' take shape generally remained from view in modern architects' ideological discussions. They disappeared 
into abstractions of people and everyday life. Many of these texts implicitly but sometimes also quite boldly reduce users to passive, predictable and obedient actors with constant and universal needs (Michl, 1995).

In response to such determinist tendencies of modern architects, scholars became increasingly interested in how modern architecture is lived (see e.g., Boudon, 1979; Avermaete \& Casciato, 2014; le Roux, 2014). Their studies showed the complex interweaving of activities between designers, builders and users in how the built environment becomes part of everyday sociality. But, instead of dealing with architecture's contingency, Till (2008) claims, architects always have evaded and continue to evade it: retreating instead into more controllable aspects of design - the aesthetic, the technical. Elsewhere, he points out that architectural culture, today still - as evident in awards, reviews and publications - prioritizes the visual and technical and suppresses more volatile aspects of architecture related to processes of production and use (Awan et al., 2011, p. 29).

Till's observation aligns with findings from ethnographic studies of contemporary architectural practice and design processes (Cuff, 1992; Imrie, 2003; Verhulst, Elsen, \& Heylighen, 2016; Van der Linden, Dong, \& Heylighen, 2018). These studies focus on architects' relations with users, and show that they often rely on abstractions of people. In Verhulst et al.'s (2016) case study of a design process for example, the 'user' (a word not uttered by the architects) figures as a plastic entity: depending on what design aspects are being discussed, the user changes in terms of abstraction and characteristics - from very abstract, without a specific body/gender/personality, to a particular person.

While architects' relations with future users have been subject of repeated interest, to our knowledge few studies of architectural design processes focus on how architects anticipate how use takes shape - how their designs generate (social) consequences. This is where our interest lies. Starting from the idea that, even if architects may evade complexities of design-use in their writing or prioritize aesthetics and technique, they must somehow be aware of/ confronted with design-use complexities. Building on the ethnographic studies, we seek to develop insight into how architects deal with these complexities during design.

\section{Methods}

The study fits in with a series of case studies focusing on one particular real-world design project or firm at a time (e.g., Schön, 1984; Cross \& Cross, 1996; Yaneva, 2009b; Dogan \& Nersessian, 2010). Such studies foster detail, richness, and in-depth understanding of a phenomenon in real-life context (Flyvbjerg, 2006).

As mentioned, our explorative case study inquiry is built around the design competition for a new media building in Brussels. We chose to build cases around a design competition because (1) competition design processes are usually well documented and (2) doing so strengthens cross-case analysis. Interesting about this particular competition is that the client produced a documentary series about it, Reyers $2020 .^{2}$ The episodes feature 30 -minute portraits of the participating

\footnotetext{
${ }^{2}$ See https://www.canvas.be/reyers-2020
} 
architecture firms, showing (parts of) their design process, design media and workspaces. Although we should keep in mind that the series portrayed these firms through a specific lens, it offers exceptional material: having video recordings of architectural design processes available for analysis is rather unusual. Also, considering our study's explorative nature - we seek to identify opportunities for connecting theoretical work to design practice rather than to theorize a particular phenomenon - the series offered a focused start providing pre-insight into architects' concern for use.

A case then, is defined as an architecture firm that participated in this competition (often in collaboration with other firms). Based on the documentary series we selected three of the five participating firms for in-depth study, aiming for a maximum of diversity in their approaches to anticipating use: De Vylder Vynck Tailleu, OFFICE Kersten Geers David Van Severen, and Robbrecht en Daem. ${ }^{3}$ Each case study focused primarily on the design process of the competition design and its outcome (fig. 2, 3 \& 4), but also probed the architects' and their firms' way of working more generally.

Besides the Reyers2020 episodes about these firms, we collected two more sources of evidence: (1) design documents including the firms' competition entries, models and the clients' design brief and project dossier, and (2) three semi-structured in-depth interviews with four partners from the three firms conducted by the first author after the competition was concluded. While the interviews form the core of our analysis, the additional sources of evidence gained us a more comprehensive view of the phenomenon under study and increased trustworthiness (Guba \& Lincoln, 1985) e.g., by mitigating issues of post-rationalization.

The interviews with Paul Robbrecht and Kersten Geers and David van Severen took place at their offices. The interview with Jan De Vylder, after a quick visit to the office, took place across the street from their office in a quiet coffee bar. The interviews lasted between 1 and 1,5 hours and were conducted in Dutch. They were fully transcribed and analysed qualitatively and iteratively following (aspects of) QUAGOL (Dierckx de Casterlé, Gastmans, Bryon, \& Denier, 2012). This method is particularly suited to analyse interview data. It aims to support researchers in developing holistic understanding of interviewees' responses and keep researchers from over-relying on analysis software. Doing so QUAGOL starts with an extensive preparatory phase, 'paper and pencil work', that precedes the actual (digital) coding phase. Following this methods the first and last author started the analysis with a thorough multi-stage reading process and independently developed concept schemes for each interview. These schemes informed a preliminary non-hierarchical list of codes that was assigned across interviews using NVivo analysis software. This list of codes was iteratively refined and integrated into a story line in response to our research question by identifying hierarchies in the form of categories and themes. This storyline is presented next. All quotes presented have been translated to English by the authors.

${ }^{3}$ All three firms participated as part of a temporary association:

- Architecten devylder-vinck-tailleu + evr-architecten

- Office Kersten Geers David Van Severen + KCAP

- Robbrecht en Daem \& Dierendonckblancke

The design outcomes need to be seen as the outcome of intense dialogue between these firms. 


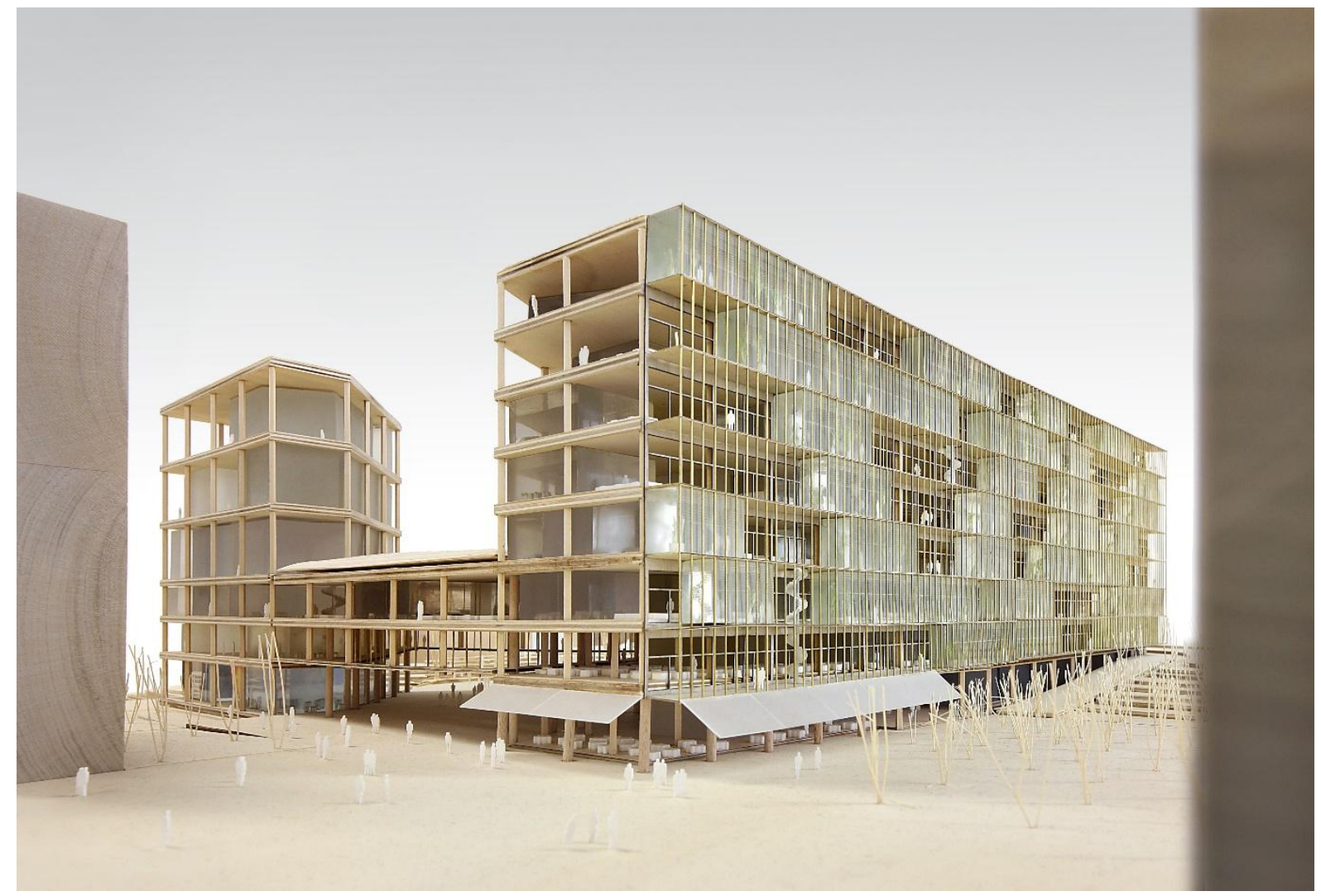

Figure 1. Model Robbrecht en Daem \& Dierendonckblancke. Photo: Filip Dujardin.

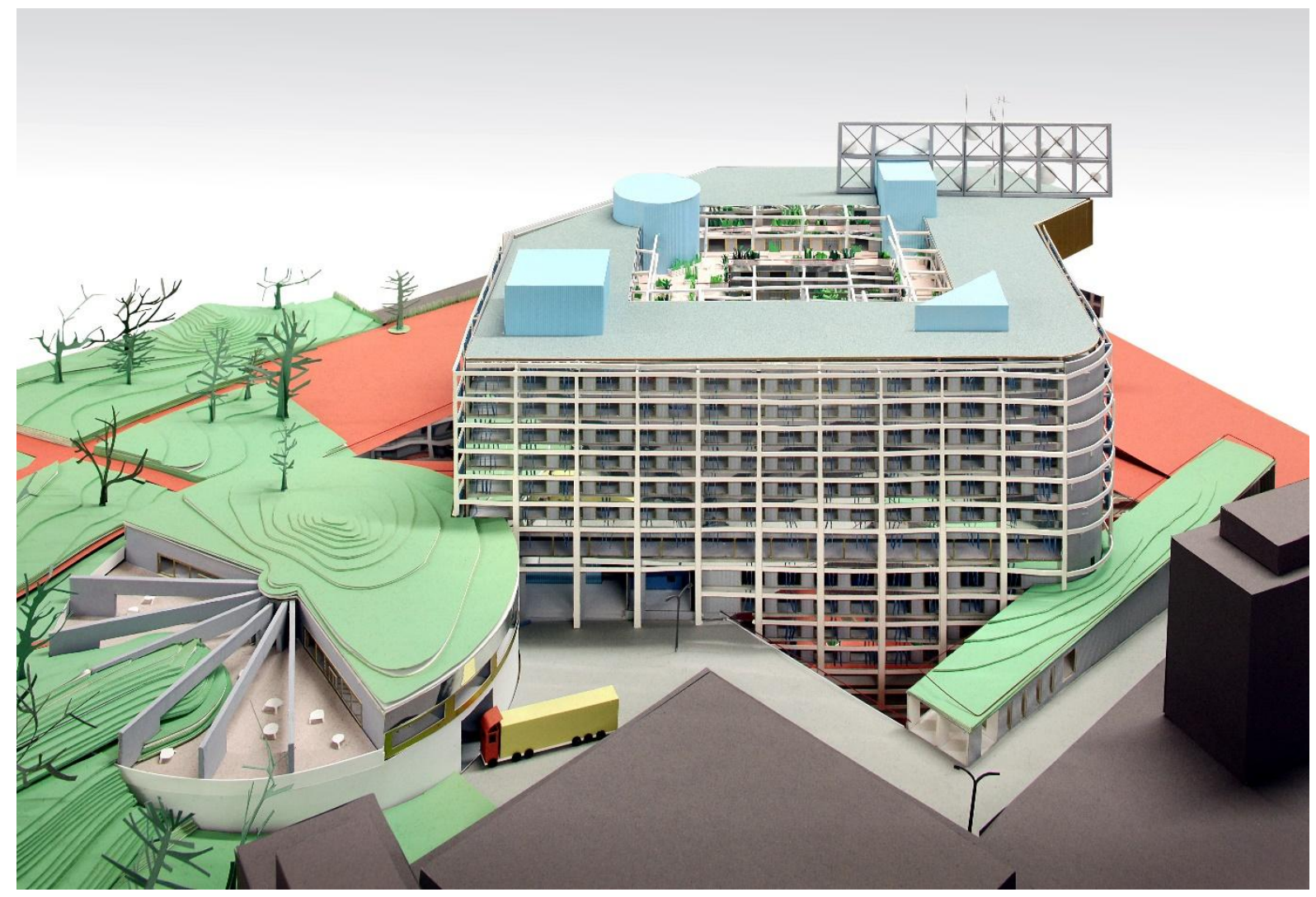

Figure 2. Model architecten devylder-vinck-tailleu + evr-architecten. Photo: Filip Dujardin. 


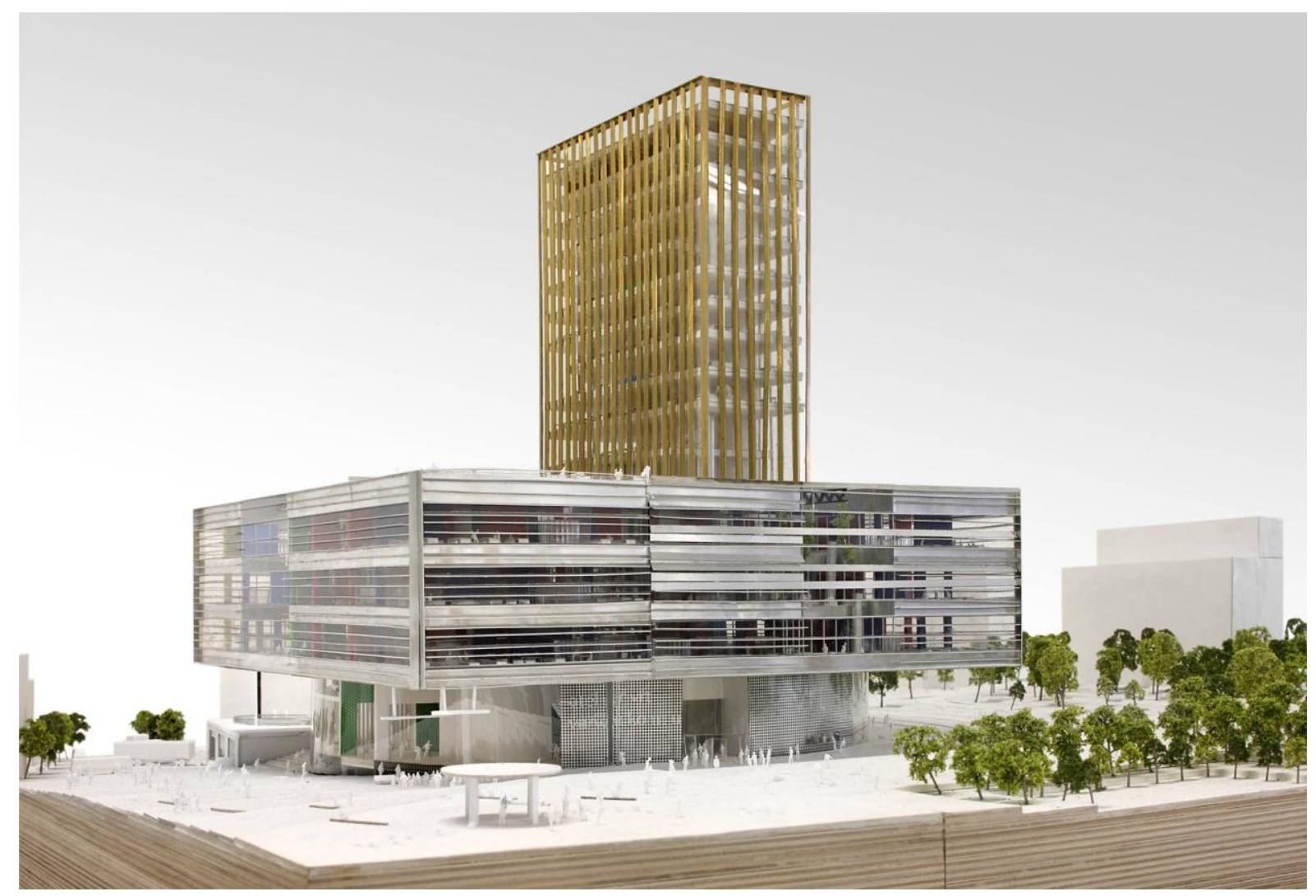

Figure 3. Model OFFICE Kersten Geers David Van Severen + KCAP. Photo: Filip Dujardin.

\section{Findings}

Below we report on how the interviewees and their teams deliberated and dealt with design-use complexities. First we address their awareness of the media buildings-in-design's social role. Next we present how they know about the relations between their media building and its future users. And finally on how this knowledge found its way into their designs.

\subsection{Awareness of social influence}

Evident in the competition entries and interviews is the architects' awareness and conviction of architecture's intimate link with social life. And of their own influence on social outcomes. Many examples illustrate that they connect particular and different types of social outcomes to specific design choices. Sometimes social outcomes are even explicit design concerns. In Robbrecht en Daem \& Dierendonckblancke's competition entry we read: "In further detailing the plans we would like, in consultation, to 'hide' more staircases in order to dissuade elevator-use in favour of stair-use." When asked to explain, Robbrecht brings up another example of a different type of influence:

Also by making interesting staircases - interesting to take them. And also the feeling of a building where you're in touch with the top floor. Where you've the feeling 'I belong here when I work and create, but I'm also part of a large community.' That's something that we want to achieve. That feeling that if you'd be in that building that you're part of a larger whole. [...] To give people this feeling through the building, that was one of the matters that we [aspired]. 
Spatially, the vertical openness of their media-building is to evoke this feeling which relates to employees' social role and relations (fig. 5).

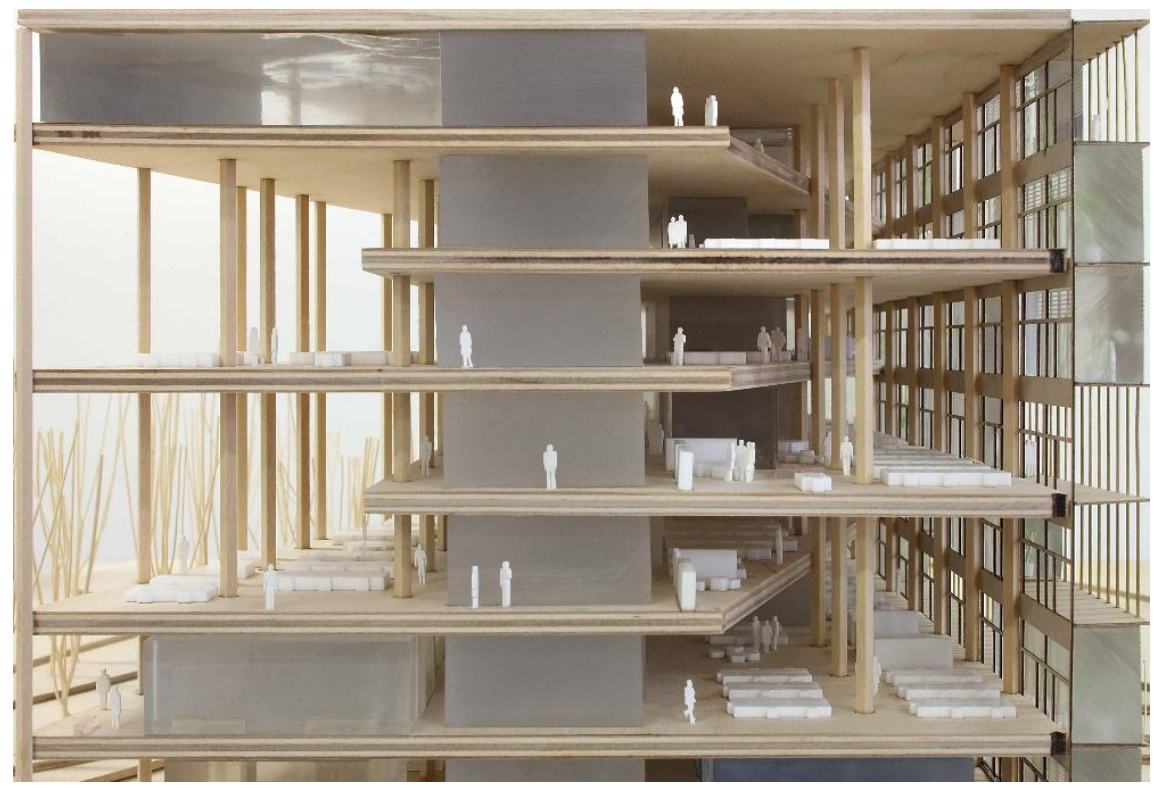

Figure 4. Robbrecht en Daem's vertical openness. Photo: Filip Dujardin.

These fragments show how it is almost self-evident for Robbrecht that, through their architecture, they influence people's behaviours and relations/ roles. In the interview yet another type of influence comes to the fore: Robbrecht ascribes the building-in-design a role in shaping the media as a cultural phenomenon:

Yes, it's more than studios and meeting rooms and so on and so on. That it also means something, or should mean something in the cultural field of Flanders. [...] But maybe even wider than that ... in Europe. And that there'd be a possibility, like it used to be before and then passed, that the public would be much more involved with that building. And this is why we built that giant piazza.

This media-building-in-design should not only reflect media production and consumption as Robbrecht observes them today but, through the piazza, should also shape public engagement with the media.

Also in comments and writings of the other architects we observe the (often unspoken) presupposition that through their designs they assert significant influence on the social context. This presupposition is also present in the client's communication. In the design brief the VRT asks for a building that not only reflects but also actively fosters change in their organization. An important aspect of the assignment is generating new work structures: "the new building is a physical and symbolical anchor for the many changes which the VRT has started towards a new way of working (together) and a more efficient and flexible organisation." De Vylder interprets: "they expect the building to generate different ways of working." 


\subsection{Specificity \& openness}

When thinking through use the interviewees and their teams follow two different but related lines of thought: specificity and openness. In their competition entry OFFICE \& KCAP introduce their design as follows: "The architecture is both open and specific and offers a frame/ basis for the media today, tomorrow and in 20 years, knowing that these media develop in breath taking pace." When Geers and Van Severen are asked to explain, it proves to be something rather difficult to put their finger on: "In the end we try to be very specific with the architecture but to leave a lot open. And that, of course, is a very vague explanation of what a building could be..."

Specificity relates to how the media-building-in-design facilitates particular uses. Use in a direct sense - i.e., how the functional program finds place, and in a more indirect sense - i.e., how the building influences processes of media production/consumption and the people involved. By detailing the design for use (in terms of physical characteristics) architects inevitably but also possibly deliberately afford or constrain certain social outcomes. The architects seem well aware that focussing too narrowly on specific outcomes risks that the architecture becomes coercive - i.e., can be used comfortably only for specific functions in a specific way by a limited group of people.

The more specific the design (focus), the more difficult it is for a building or space to respond to the unexpected and unforeseen - i.e., to diversity of use(r)s as well as changing contexts, e.g., related to social and technological change. These architects' weariness of being too specific/ coercive shows in their references to functionalist architecture. Without exception they all mention the 'grand masters' of modern architecture with great reverence. At the same time they, also without exception, are sceptical towards these masters' paternalist ambition to realize certain social programs. In these references the architects emphasize the importance of offering flexibility, freedom - literally space - such that life can unfold. So their designs need to be specific, yet simultaneously 'open'. De Vylder:

We try to give our projects an open end as much as possible. This means that many things may also go wrong, things that you'd not foresee in that way as a designer. But from which you also have to say, it doesn't harm it. It rather makes it more interesting. I'd not have done it that way, but actually it's no madness at all. But it's not how - as an architect-you'd have solved the problem in the beginning.

Thinking future use from this idea of openness is found in the design considerations of all interviewees. They are much aware that they need to create a building which can respond to the unexpected and unforeseen - e.g., Robbrecht: "...and then you do have to make a building that's very flexible. That, time and again, can be used differently, in which not too much is fixed and predetermined."

In case of the media building, the unexpected and unforeseen the architects refer to relates sometimes to the diversity of users and reinterpretations of function (like in De Vylder's quote), but predominantly to the rapid technological advances in the world of media production and consumption: nobody knows what the media will be like in five years' time. These architects explain how their design needs to be specific enough to offer necessary conditions to support media practices as they happen today (or as these architects envision them), but also sufficiently open for the media to unfold in unpredictable ways. 
As the coming paragraphs will detail, anticipating use entails continuously exploring and testing solutions between openness and specificity. Seeking a balance, these architects repeatedly ask themselves how open their design can be, such that it can still support specific use practices (e.g., meeting colleagues, recording or editing video's). And vice versa: how specific can they be in imagining use such that different interpretations (e.g., by users or the client) remain possible? These questions are explored continuously. Often together with other actors: depending on the context (e.g., a competition design) these architects describe how specificity grows into the project, both during and after the design process - first in interaction with the client, the design team and other experts, prospective users, builders. And eventually, over time, in relation with users.

Striking is how these architects' attitudes vary: important differences exist in the role they ascribe themselves (and with that other actors). Whereas Geers and Van Severen focus on creating as much openness in their designs as possible, for Robbrecht and De Vylder imaginations of use are a starting point for design.

\subsubsection{Attitudes}

Deeply engrained in OFFICE's work is the following philosophy:

We see architecture as frame and content. And that those are constantly related to each other. Life [content]... yes, you can't really design life. It needs to be able to unfold. [...] And for us architecture is rather 'frame'. And content is then something you can't define. That has often been tried, but... rather a feeling of, look, you need to give it space. And space, what's that for us? That's of course exactly what architecture is.

This philosophy seems to contrast the approaches of De Vylder and Robbrecht, who - in Geers and Van Severen's wording - primarily approach their designs from 'content'. De Vylder explains: "we try to approach everything, not from the program but from scenographies that frame life." These scenographies can be seen as detailed scenarios of use practices, experiences and meanings - De Vylder illustrates their approach with a student exercise:

We ask not to design kitchens, but places where we'd like to cook together. And where, on early Sunday afternoon, we'd put the finishing touch to the appetizers while friends arrive, whom you serve - in that kitchen - a glass of white wine, cold white wine in expectation of a delightful afternoon.

Similarly Robbrecht explains how to him architecture, as a profession, is about "how people are together in a building". At the core of Robbrecht's design considerations is imagination of use, people's doing and being - about the media building he says:

But...it...yes, that you're not in a situation where you're locked away with your monitor...but that it's a sort of life that you need to imagine as a designer, of people who are occupied with production and computer screens. And what would they desire from the kind of surroundings they want to work in? It was leading in designing the new VRT building, but also in the concert building, to mention our two biggest projects: trying to gain insight into the communication between musicians and the audience - how to envelope this?

Whereas Robbrecht and De Vylder primarily approach architecture as the actions, experiences and meanings taking place there, Geers and Van Severen hesitate to speculate about use - about how their buildings will be lived. They express their fascination with the unpredictability of how media production and consumption will change over time. They seek to develop what they describe as 
"independence between function and architecture". This is for example reflected in their design of a villa with uniform rooms - "a villa with rooms that all have the same dimensions, in which really anything can happen." For them a building is successful when its spaces are easily (re)interpreted and appropriated during design by the client, but also after design by users through time.

You determine certain things. That's the 'figure ground' - what we said about life and the frame, and so on. And then in the process, in relation with the client you determine many other things. You maintain the frame, while that what's specific grows in that frame in relation with the client. When, during that process, the building doesn't significantly change, then it's successful.

In their design of another media building, ${ }^{4}$ they for example explain, a radio studio became a garage without requiring radical changes to their design. They apply this philosophy also to the VRT's quest for realizing 'the new working'. They stress the independence between people's ways of working and the architectural design:

In so far as you make a building, whether it's a house or a building where people work or do something different. You can create a frame. How they work will only have a limited influence on how the architecture looks - or at least we don't believe so.

This contrasts with Robbrecht's approach which starts by imagining what it would be like to sit behind your desk as a VRT employee, absorbed in your monitor.

Complete independence between architecture and function and use, Geers and Van Severen are well aware, is impossible - especially, they explain, in largescale complex projects like a media building. Frame and content are always interrelated: "You can't pretend the functions that are asked don't influence the design process. So, in functions, you always have bigger and smaller elements, bigger and smaller rooms, and so on." The inevitable and minimal way in which architects influence and co-shape the social context, they believe, is through physical structure - a condition to make a building into a reality. And by defining something as space - making the design specific - you influence how the building and spaces will be used and experienced:

In the end you make a building which has a structure. And that structure can be in the form of rooms or... but hé, it needs to stand, a building. This structure determines to a large extent the spaces. And there's an enormous impact of that structure on use, on how you are in that space. And that, we find interesting.

Thus, although Robbrecht and De Vylder primarily approach their designs from 'content' (actions, experiences), and Geers and Van Severen from 'frame' (structure), all acknowledge that, when it comes to use, architecture is and always needs to be both open and specific.

\subsubsection{Roles of others}

Part of the design philosophy of independence is that Geers and Van Severen view architecture as something that stands on its own, that does not immediately solve something for people:

\footnotetext{
${ }^{4}$ OFFICE previously participated in and won the competition of the design of the new RTS building in Lausanne.
} 
We've also always been interested in how architecture kind of stands in your way. That if you make something, you don't necessarily simply make people happy, or solve something. But that architecture is something ... that you have to learn to deal with that it's a form of obstruction."

This is also present in Robbrecht's thinking: in relation to dealing with uncertain futures he for example discusses 'stubbornness' as a quality of architecture:

You're surrounded by a continuously changing world. A certain stubbornness of the architecture that's a quality. [...] The matter-of-factness of the structure and the columns. That's...you can't simply take away a column, or it collapses. Independence from time is also a quality of architecture.

By approaching architecture this way they invoke or rely on others' active and creative interpretation and appropriation of spaces. This is what Geers and Van Severen refer to as 'solving'. Solving happens both during design, as specificity develops in interactions between the building-indesign and the design team and client, and after design, as use takes shape over time in interactions with the building and its users.

'Solving' during design - building-in-design <> designers?

Geers and Van Severen explain how the shape of a building sometimes 'simply' is a choice, in which use must be solved:

In that sense use and architecture have a very difficult relation... well, maybe not difficult, but you must dare to make it. So eventually we say: there the circle is the right form. Yes, that is a choice. A very specific choice. But in the end that shape needs to facilitate that the public can enter.

'Solving' during design - building-in-design $<>$ the client?

To develop specificity into the design, the relation with the client is without exception marked as very important. De Vylder describes how fostering 'the new working' requires being very specific in both idea and space about what it entails and thus intensively interacting with the client. And he is adamant that this interaction cannot be replaced by a good design brief as it allows an iterative testing and exploring between idea and space. He says: "How can I know what this 'new working' is for you...that's for me a mutual testing/ exploring."

Such intensive interaction is not always possible. In design competitions for example, communication between client and architects is often limited and open to the other participants. De Vylder regrets that when such interaction is lacking, architects often resort to very general, high level (open) design solutions (e.g., landscape offices). But, he goes on, in order to actually realize change (e.g., new working) the design requires a certain specificity. Moving beyond such 'fake solutions' is however risky:

You could say that because they themselves [client] aren't specific in the idea of 'new working', they expect towards the building. OK, then you go for it. I mean, you try with that knowledge that I just explained of banks, you try to project [in your design] the examples you hold in your mind. I take that very far. And the further you go, the more apparently you're too much in one direction, that they don't want or.....

'Solving' after design - building <> users:

Geers and Van Severen see a very limited role for themselves in determining use: it is in the interactions with the client and eventually in the interactions with users that a space attains 
meaning. A place becomes a workstation when someone sits down in that place and opens his or her laptop. About their own office Geers and Van Severen: "Look around, our office, it's just a room and you open a laptop. And then you simply sit down somewhere else."

As described earlier, the minimal way in which they believe to influence use is through the preconditions of structure. Users interpret and appropriate spaces in their own way, but in doing so they are bound by material conditions. The challenge they see for themselves is to "cleverly" design buildings' structures to have affordances, but not fix how or for what spaces will be used. That is for the client and eventually future users to decide.

\subsection{Strategies}

The interviews and competition entries revealed several strategies to create designs that are specific (so as to support specific outcomes) and open (so as to respond to the unknown).

\subsubsection{Strategies related to developing openness}

To create openness Geers and Van Severen seek a 'figure ground' - which can be seen as an exploration of the necessary/ minimal conditions for particular practices - e.g., having a meeting, recording or editing video. They ask themselves:

Here [VRT], but again, also with the RTS, we take it as a challenge: is there really such a big difference between, say, a meeting room and a sort of recording studio or a small studio? Are these not simply rooms of a certain dimension?

Seeking that figure ground, they let themselves be guided by buildings' structural preconditions, which as mentioned earlier, they believe to always have an impact on how you are in a space and on what you can do there. Focusing on structural preconditions, they explain, automatically creates certain use potentialities, affordances. They probe these affordances as a range of possible ways for the program to unfold within the created structure:

What interested us is that this enormous width, that 80 meters, you need a sort of structural intervention to carry that 'box' [atelier volume, see fig. 6]. And then, again, you get a sort of big room, small room logic - something that always fascinates us. [...] That's recurrent in many of our projects. And also here, this also almost automatically makes that smaller studio's - those self-cabins, those postproduction cabins - easily find a place there. They don't have to be there, but they could be.

Spatially this means that they "look for elements that define the space, but not definitively determine the function." Since in large-scale, complex projects like the media building it is impossible to develop full independence between architecture and function, Geers and Van Severen aim to create a variety of 'conditions', which relate to the building's different volumes:

So you make a number of conditions: here at the ground floor [points at the studio's, see fig. 6], and you have that 'box' where everything is very high - so high that you can easily place a double floor [ateliers], and then you have a condition where you're much higher, that you always look outside [tower].

The conditions they create specify neither function nor shape of a space. Geers and Van Severen explain that their designs for the RTS and the VRT feature the same conditions, but are very different buildings: "compositional this is similar and yet, the result is very different." They link this notion of 
'conditions' also to the concept of 'type': "it actually is searching for types of spaces. So types rather than literally the shape of spaces."

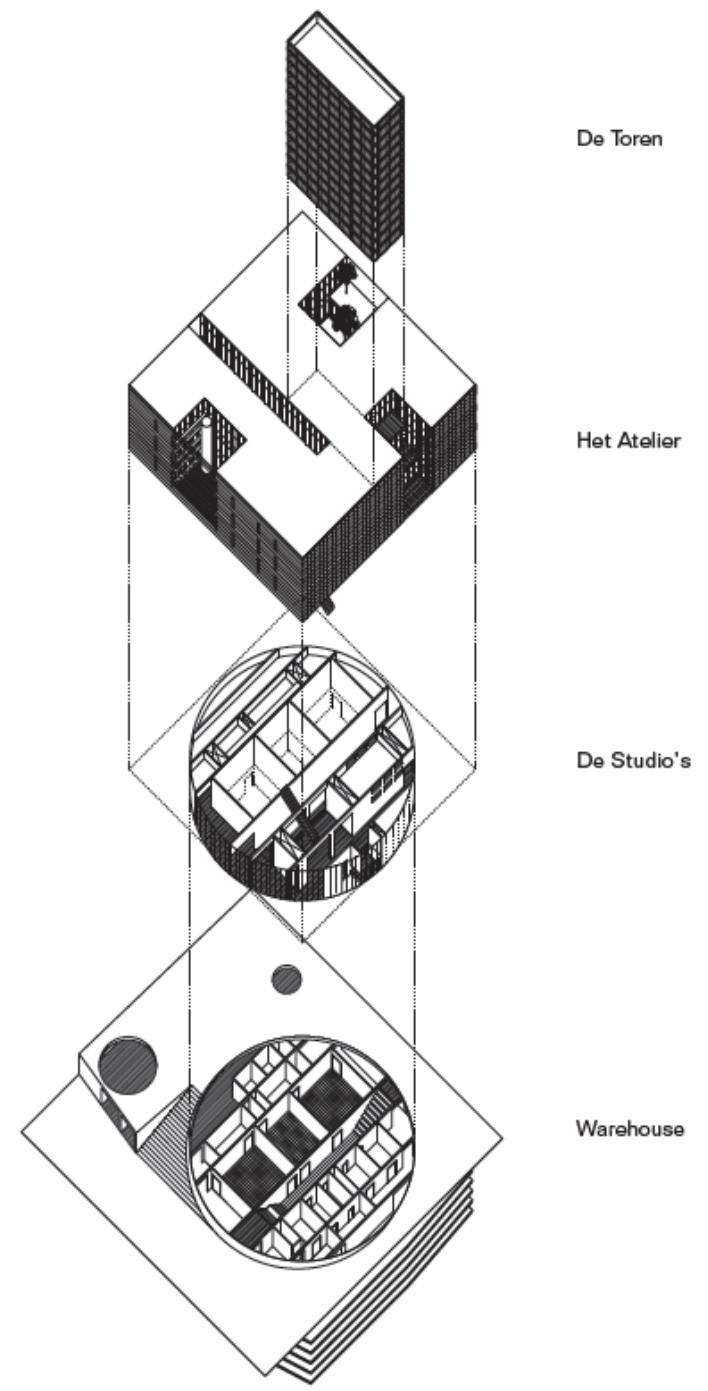

Figure 5. OFFICE's exploded view of volumes. Competition entry OFFICE \& KCAP.

Geers' and Van Severen's search for 'conditions' in order to create open designs, shows similarities with what Robbrecht describes as developing a 'clarity' in his designs:

It really isn't that malleable, architecture. That means, you have to develop a certain clarity, a certain openness in your buildings. That certain other things, which you hadn't expected in the slightest way, that those things can come there and happen there. But that also makes architecture interesting.

Developing this clarity, like conditions, is about searching for spatial qualities. These qualities are, to a certain extent, disassociated with function. Recurring elements across the interviews are:

- Proportions, dimensions

- $\quad$ Light conditions

- Sound conditions 
Mentioned less often:

- $\quad$ Routing, relations between spaces

- Relation with outside

- Repetition

- Emptiness

This search for conditions/ type and for clarity is informed by architectural theory often through reference projects. Robbrecht for example tells us: "look at very old buildings, Roman buildings. Those are very clear and we can still use them today." And, "there's something about the classic space that allows a lot throughout time."

\subsubsection{Strategies related to developing specificity} The interviews reveal multiple strategies to develop specificity into their designs. One strategy operates at firm-level and relates to the acquisition of projects. According to De Vylder, his firm deliberately keeps accepting small-scale projects to stay in contact with human-architecture relations:

I always say: who can build a house, builds a school in a different way. So the maintaining of the building of houses should be a continuous leidmotiv in a career, because it constantly informs you about the state of human proportion. It's important to continue to make this exercise. To better understand relation human-building...or give a chance, or change. And to see buildings not only as buildings, but as places to work, to live, to sleep."

Other strategies operate at project-level. We have already shown that both Robbrecht and De Vylder depart in their designs from use scenario's. The competition entries, and interviews with Robbrecht and De Vylder feature numerous scenarios, anywhere from a few words to quite extensive images of use and social outcomes. This scenario-thinking is a strategy of imagination. Besides by interactions with others, their imaginations of use are informed by a variety of sources:

- $\quad$ the design brief

- observations

- life experience.

All interviewees highlighted the importance of the design brief but simultaneously point out its limitations in developing an intimate understanding of 'how people are in the building-in-design'. Crucial for De Vylder are observations of how people (e.g., the architects themselves) interact with buildings:

When you're an architect, in your life you have to continuously... I believe... no matter which building you enter and what reception desk you approach ... and then unconsciously capture how that happens. What you think is good and what you think isn't good. [...] A sort of subconscious knowledge that isn't in the cahiers, but that is produced by the observation obsession, which as an architect you have to live with. I think that as an architect you need to continuously observe everything. And need to draw and write everything...but make that observation immediately... not make it analytical. It is rather about sensing that distance to the desk, how you step, how you walk, and whether you like it or not when you saw light 
behind the desk, or looked into the backlight. I think that's what an architect needs to do: observe. To take that into account when it matters.

In these imaginations of use and social outcomes, not only their experiences of architecture play a role, but also experiences more generally - e.g., experiences of music and art, of friendships are important in Robbrecht's designing: "You try...you have a very personal feeling. And you put very much of your own, l'd say, everything that you have experienced in your building." This underscores design as a very personal matter. Particularly, so it seems, when it concerns things that are difficult to grasp: the actions, experiences, meanings that Robbrecht tries to give form through design.

De Vylder's account of how they designed the entrance of their media building gives a good impression of how use scenarios take shape and are translated into spatial design: "For me in our design it was very clear that, when someone would approach the reception desk, that he'd need to see the person behind that desk and immediately also beyond have a tremendous insight into the building." Throughout the interview De Vylder brings up various influences which informed design choices that relate to this 'entering-scenario':

What is this based on? It's based on experiencing desks, on having seen things, having seen things work differently and so on. So how do you take that into account? It isn't the case that I was leafing through my notebook to see all the things I ever wrote about desks. It was just a feeling. That then also came together with the fact that in the brief they asked for a reception that should also give a feeling of the entire building....so those thing, they come [together]..."

These insights from observations, experiences and the brief often appear in design processes via reference projects. In the accounts of the interviewees different types of buildings serve as a reference for use. Most buildings serving as a reference in designing the media building are projects that they visited:

- $\quad$ Buildings with a similar program - i.e., other media buildings.

- 'Random' buildings (most frequently mentioned). Random in the sense that these buildings not necessarily directly relate to the project at hand e.g., in terms of program, style. It often concerns buildings that the architects happened to visit or otherwise came across in earlier studies or projects.

- Architects' previous projects. Particularly interesting, for example, is the importance Robbrecht attaches to their own office building in other designs as it comes to thinking use. $\mathrm{He}$ is one of the designers, but also has a lived experience of it. Moreover this experience is shared by all the others working in the firm.

- Combinations of the above. De Vylder, years earlier visited the media building in Bratislava which now became an important reference; Geers and van Severen designed and won the competition for the RTS media building in Lausanne, which was one of the reasons to participate in the design competition for the VRT.

Scattered throughout the interview, De Vylder discusses five reference buildings that informed the design of this scenario (which, important to note, is not tied to one functional space). He compares two experiences of reception desks in bank buildings: 
...then you can visit [Arne] Jacobsen's national bank. Copenhagen. You enter in a gigantic static space that blocks movement. Yes, I can go there and I can go there. Whereas, this summer in Toronto, when I visit Mies' bank in Toronto, you enter a bank, and before you know it you're between open offices. And then you walk and say 'oi, I'm sorry, I walked past the desk.' 'No, no, that is our intention, come on in.'

Furthermore De Vylder discusses the Bratislava media building he happened to visit years earlier. He describes how that building's lay-out offers immediate insight into the building: "Ok, past glory, whatever it may be, true. But you could still uncover the building's ambitions. And that's what you remember. And sooner or later it comes back in the way that you [design]..." The building's typical form (fig. 7) inspired the atrium-shaped inner space of their VRT design.
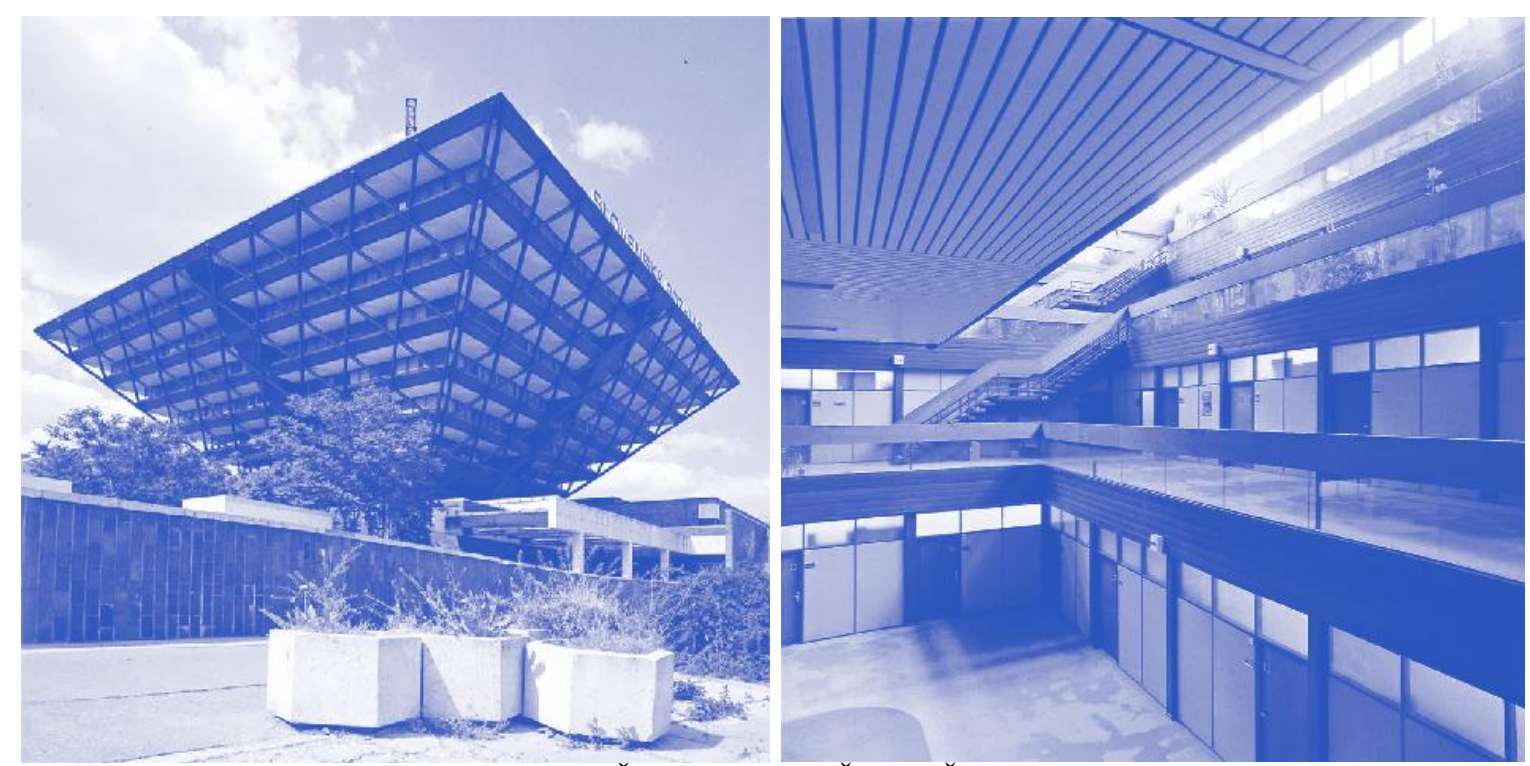

Figure 6. Slovak Radio Building. By Štefan Svetko, Štefan Durkovič and Barnabáś Kissling, 1983. Via the competition entry by dVVT \& evr-architecten.

Later in the conversation he explains about their design's relatively small entrance door. After much discussion they choose to create this small entrance - smaller than one might expect in such a grand project. De Vylder mentions a monastery by Dom Van der Laan and Zumthor's museum Kolomba in Cologne to explain that a small entrance door can reinforce, dramatize, the experience (of an overview of the building) they want to create.

Although it is difficult to put a finger on how scenarios exactly take shape and how they are translated into design, De Vylder's account reveals a rather organic, associative - not analytical process, in which he moves from example to example (reference projects) that brings together all kinds of influences. Also, although more explicitly in Robbrecht's account, it is a deeply personal process that is difficult to share with others: internal and sometimes even instantaneous.

I try to understand and absorb as much as possible. Then there's inspiration. Nona seconds. It's often the case that I've seen someone, who asks me a question and possibly becomes my client. And the place. And then I drive home in my car and at that moment the building already starts to exist somewhere here [points at his head]. The first time you talk to someone about who'll be the actual user of that building. And also the place... You need to [overlap] those two. The site. The two. And then something happens, something starts to develop. And for me it goes literally like that. [...]The biggest part is - it's not like that I draw on a piece of paper what I...no: you're making it in your mind." 
I'm not someone who easily puts something on the table to talk about it. ...After a week I'll say 'this is what I came up with, what do you think about it?

\section{Discussion}

Clear is that the social outcomes of their building-in-design - use - is an important and recurrent aspect throughout the design processes of these architects. In applying the distinct but related lines of reasoning of specificity and openness these architects engage with design-use complexities; with having influence on use (specificity), but no control over it (openness).

Developing specificity into designs can be interpreted as a strategy to direct certain outcomes: in a very direct sense it is about how the program finds place in the media-building-in-design. And in a more indirect sense it is about how the media building affects processes of media making/ consuming and the people involved. The findings show that the architects are concerned with the latter on different levels - e.g., they imagine the role of their design in people's behaviours, social roles and cultural meaning. Scenario-thinking is important in this: the firms and architects give many explicit descriptions of hypothetical use. This attention to use, however, is scattered throughout the design process and somewhat intangible. However important and present, attention to use is difficult to pinpoint as clearly delineated activities during the design process. The interviewees for example never referred to these descriptions of hypothetical use as 'scenarios'. Also, there is little reflection on the different levels of influences of the building on the social context: talking about their media building Robbrecht haphazardly discusses how the design influences stair-use and how it mediates employees' relationship with the VRT. Furthermore pointing at this 'unstructured-ness', and found in other studies as well (Imrie, 2003; Verhulst et al., 2016), is that in these hypothetical descriptions of use, the architects talk with very little definition about future users - e.g., they remain bodiless, genderless, ageless, etcetera.

Developing openness into designs can be seen as a strategy to cope with architecture's contingency: creating a building that can be interpreted and appropriated in different ways through changing contexts (e.g., survive technological change in media making). This observation gives some nuance to Till's claim that architects evade contingency. If we understand designers' influence on the social context as a consequence of (deliberately or not) inscribing certain assumptions about how their design will be used, by whom and in what context (cf. Akrich, 1992), creating openness can be seen as a deliberate effort to not inscribe such assumptions. What that spatially entails, however, remains quite vague. As reported, in the attempt to create openness, the architects focus on architecture's atemporality: how it is also independent and unaffected by time. And they refer to the importance of (among other things) proportions, light and sound. Given this focus and these references, openness can be related to the notion of type - something Geers and Van Severen do so very explicitly. We will discuss this link more elaborately further on.

While openness and specificity can be seen as strategies, they are not in a very outspoken or deliberate way - witnessed by the difficulty Geers and Van Severen experienced to explain what they meant by their design being both open and specific, despite its literal description as such in 
OFFICE \& KCAP's competition entry. More research is needed to come to grips with specificity and openness: are they indeed strategies or thought structures in designing - thinking tools? Or can they actually be attributed to specific particularities of physical designs? Or are they qualities of the relations between people and buildings?

Also, our study sheds little light on the relationship between specificity and openness. While sometimes opposed, they also appear in these architects' accounts as completely separate lines of reasoning. An interesting lead might be Boon et al.'s (2018) suggestion to consider different levels on which designs can be open or more directive when it comes to use.

In developing specificity and openness these architects use knowledge of human-architecture relations. Our study gave some insight into how they know about how buildings, through their physical particularities, affect people's being and doing. And into how this knowledge finds its way into their designs.

Three sources of knowledge surfaced in the interviews. Firstly, De Vylder stipulated the importance of doing small-scale projects. Although he gave little further insight into this, this might be related to that often the client of such projects is also one of its main future users.

A second source mentioned is architectural theory. Particularly the notion of 'type' is brought up by Geers and Van Severen in relation to developing openness into their designs. The significance of type for architecture has been studied by many authors in many different ways (for an overview see Panerai, 1981). Key figures in this discourse, e.g., Argan (1963) and Rossi (1982), often still refer to the, as Rossi notes (1982, p. 40) 'masterly' definition by Quatremère de Quincy from 1825, who opposes type to the notion of model. Like a model, type is an object after which something else is made. But whereas a model is a form to be copied or perfectly imitated - "everything is precise and given in the model" - type is the idea or ideal embodied by an object that serves as a rule for the conception of works that do not necessarily bear any resemblance - "everything is more or less vague in the type". Type is long since recognized as a strategy for concept generation. It enables architects to profit from knowledge about past solutions to related architectural problems (Rowe, 1982). This knowledge finds its way into design not expressed as rules, but rather takes the form of architectural objects that embody essential characteristics shared by a family of buildings (Loeckx \& Verpoest, 1993, p. 142). These objects function as examples. Their characteristics can address any aspect of architectural design, but mostly concern the spatial distribution of functions. Starting from a specific type, architects thus more or less know what the spatial configuration of the building is going to look like (Heylighen, 1995, p. 27). We recognize this in the accounts of Geers and Van Severen: the RTS and VRT designs share the same type, and the RTS design functions as key-example for the VRT design. What is less clear however is where this specific type comes from. From their accounts it seems they use type in the form of architectural example, but also as a specific way of reasoning to deal with architecture's contingency. Their search for 'necessary conditions' for certain functions to find place certainly conforms to the idea of type as essential characteristics. However, more research is needed into relations between type, openness and contingency. Type as a way of reasoning might connect to Madrazo's (1995) work, whose comprehensive study of the conception of type in architecture also investigates type as a mind structure in creative processes. 
Third, these architects' own experiences are very important in their knowing about humanarchitecture relations. These experiences, the study shows, relate to specific architectural objects (reference or the firm's previous projects) but also life experiences in general. This is found also in the other studies of architecture practice mentioned earlier (Cuff, 1992; Imrie, 2003; Verhulst et al., 2016; Van der Linden et al., 2018), which uncover how architects often project their own experiences onto future users. This is considered problematic in the light of people's diversity. Consequently in these studies less attention goes to architects' own experiences as a valuable source of knowledge. Our study shows that in finding out about human-architecture relations architects' own experiences are a very important and rich source of knowledge. At the same time, the knowledge gained through their experiences seems to be rather elusive. They describe this knowledge as something subconscious and internal. Learning about human-architecture relations for them is not analytical or scientific: they explain it as a 'sensing' or 'feeling out' what happens in the interactions between people and buildings. Consequently, most clearly expressed by Robbrecht, this knowledge is difficult to share with others e.g., team members or the client. It 'emerges' in design processes unsystematically through intuition, or indirectly through examples - reference or previous projects. This fits what we addressed earlier about developing specificity into their designs.

\section{Conclusions}

We inquired how architects deal with design-use complexities in practice. Standing out in the findings is that, while use is a very important aspect for the interviewees and their teams, their attention to use during design seems rather unstructured. And, their knowledge of how buildings affect people's doing and being although rich, might be best described as elusive, finding a way into their designs through intuition or indirectly through example, reference or previous projects.

In terms of limitations, we focussed only on three architecture firms, which demands caution when generalizing these findings to a larger group. Moreover, the analysis focuses on a design competition. Competition design processes, as the interviewees themselves point out, have their own dynamic and are governed by strict communication rules. They cannot simply be taken as representative for all design processes. These limitations are however not necessarily problematic given our objective. Our reason for studying architects' design processes was to advance the emerging discourse that tries to connect theoretical insights from STS and philosophy of technology with design practice and not so much to make grand claims about or essentialize how architects know and work.

The study, thus we believe, can provide direction to future research on how specific theories and concepts can support architects in dealing with design-use complexities during design. Opportunities where STS/ philosophical theory on mutual shaping may strengthen architectural design processes that we see, based on this study relate to bringing more structure to:

- knowing about human-architecture relations: theories and concepts that explain mutual shaping may help architects to connect with their own experiences and with what happens in the interactions between people and the reference projects they study in a more structured way; 
- implementation of this knowing in design deliberations: such theories and concepts may help to reflect on (without predicting) how specific design choices affect use, and they may give structure to devising scenarios of use;

- communication with the client and the design team about their designs' social role: theory and concepts of mutual shaping may provide architects with a vocabulary that help to explain intuitive design choices.

But more so than presenting an exhaustive list of such opportunities, what we hope to convey is the value of looking very closely to what it is that architects (already) do - how they anticipate designuse relations - in connecting design practice and social and philosophical studies of technology. In fact we believe it a necessary step to understand how specific philosophical or STS theories can be taken up productively by architects and truly become part of their design knowledge.

\section{Acknowledgements}

Omitted for blind review.

\section{References}

Akrich, M. (1992). The de-scription of technological objects. In W. E. Bijker \& J. Law (Eds.), Shaping technology/building society: Studies in sociotechnical change (pp. 205-224). Cambridge (Mass.): MIT press.

Alexander, C. (1966). Notes on the synthesis of form. Cambridge (Mass.): Harvard university.

Argan, G. C. (1963). On the Typology of Architecture (J. Rykwert, Trans.). Architectural Design, 564565.

Avermaete, T., \& Casciato, M. (2014). Casablanca Chandigarh: A Report on Modernization (Canadian Centre for Architecture, Ed.). Zürich: Park Books.

Awan, N., Schneider, T., \& Till, J. (2011). Spatial agency: Other ways of doing architecture. Abingdon, Oxon: Routledge.

Barad, K. (2003). Posthumanist Performativity: Toward an Understanding of How Matter Comes to Matter. Signs, 28(3), 801-831.

Boon, B., Rozendaal, M. C., \& Stappers, P. J. (2018). Ambiguity and Open-Endedness in Behavioural Design. Proceedings of the Biannual Design Research Society Conference (DRS), 2075-2085. Retrieved from http://resolver.tudelft.nl/uuid:e5829787-1903-4e64-baa0-fd44bc9c91fc

Boudon, P. (1979). Lived-In Architecture: Le Corbusier's Pessac Revisited. Cambridge (Mass.): MIT Press.

Brand, S. (1995). How Buildings Learn: What Happens After They're Built. New York: Penguin Books.

Conrads, U. (Ed.). (1975). Programs and manifestoes on 20th-century architecture. Cambridge

(Mass.): MIT. 
Cross, N., \& Cross, A. C. (1996). Winning by design: The methods of Gordon Murray, racing car designer. Design Studies, 17(1), 91-107.

Cuff, D. (1992). Architecture: The story of practice. Cambridge (Mass.): MIT Press.

Dierckx de Casterlé, B., Gastmans, C., Bryon, E., \& Denier, Y. (2012). QUAGOL: A guide for qualitative data analysis. International Journal of Nursing Studies, 49(3), 360-371.

Dogan, F., \& Nersessian, N. J. (2010). Generic abstraction in design creativity: The case of Staatsgalerie by James Stirling. Design Studies, 31(3), 207-236.

Eggink, W., \& Dorrestijn, S. (2018). Philosophy of Technology x Design: The Practical Turn. Proceedings of the 51st Design Research Society Conference (DRS): Catalyst, 190-199. Design Research Society.

Fallan, K. (2011). Architecture in action: Traveling with actor-network theory in the land of architectural research. Architectural Theory Review, 16(2), 184-200.

Flyvbjerg, B. (2006). Five Misunderstandings About Case-Study Research. Qualitative Inquiry, 12(2), 219-245.

Gieryn, T. (2002). What buildings do. Theory and Society, 31(1), 35-74.

Guba, E. G., \& Lincoln, Y. S. (1985). Naturalistic inquiry. Beverly Hills: Sage.

Heylighen, A. (1995). In case of architectural design (Doctoral dissertation). KU Leuven, Leuven, Belgium.

Hill, J. (2003). Actions of Architecture: Architects and Creative Users. London: Routledge.

Ihde, D. (1990). Technology and the lifeworld: From garden to earth. Bloomington: Indiana university press.

Imrie, R. (2003). Architects' Conceptions of the Human Body. Environment and Planning Design: Society and Space, 21(1), 47-65.

Latour, B. (1992). Where are the Missing Masses? The sociology of a few mundane artefacts. In W. E. Bijker \& J. Law (Eds.), Shaping technology/building society: Studies in sociotechnical change (pp. 225-259). Cambridge (Mass.): MIT Press.

Latour, B. (1994). On Technical Mediation. Common Knowledge, 3(2), 29-64.

Le Roux, H. (2014). Lived modernism: When architecture transforms (Doctoral dissertation). KU Leuven.

Loeckx, A., \& Verpoest, L. (1993). Typologie van de woning. In A. Loeckx, H. Neuckermans, \& R. Dillemans, Wegwijs wonen (p. pp.142-150). Leuven, Belgium: Davidsfonds.

Meyer. (1928). Building. In U. Conrads (Ed.), Programs and manifestoes on 20th-century architecture (pp. 117, 120). Cambridge (Mass.): MIT.

Michl, J. (1995). Form follows WHAT? The modernist notion of function as a carte blanche. 1:50 Faculty of Architecture \& Town Planning, Technion, Haifa, Israel., 10, 20-31. 
Müller, A. L., \& Reichmann, W. (Eds.). (2015). Architecture, Materiality and Society. Connecting Sociology of Architecture with Science and Technology Studies. UK: Palgrave Macmillan.

Oudshoorn, N., \& Pinch, T. (2005). How users matter: The co-construction of users and technology. Cambridge (Mass.): MIT Press.

Panerai, P. (1981). Typologieën. Een middel tot inzicht in de logica van ruimtelijke patronen. Wonen$T A / B K, 2,6-21$.

Pickering, A. (1995). The mangle of practice: Time, agency, and science. Chicago (III.): University of Chicago press.

Pinch, T. J., \& Bijker, W. E. (1984). The Social Construction of Facts and Artefacts: Or How the Sociology of Science and the Sociology of Technology might Benefit Each Other. Social Studies of Science, 14(3), 399-441.

Redström, J. (2008). RE:Definitions of use. Design Studies, 29(4), 410-423.

Rossi, A. (1982). The architecture of the city. Cambridge: MIT press.

Rowe, P. G. (1982). A Priori Knowledge and Heuristic Reasoning in Architectural Design. JAE, 36(1), $18-23$.

Schön, D. A. (1984). The Reflective Practitioner: How Professionals Think In Action. Basic Books.

Silverstone, R., \& Haddon, L. (1996). Design and the Domestication of Information and Communication Technologies: Technical Change and Everyday Life. In R. Mansell \& R. Silverstone (Eds.), Communication by Design, the Politics of Information and Communication Technologies. (pp. 44-74). Oxford: Oxford University Press.

Stender, M. (2017). Towards an Architectural Anthropology-What Architects can Learn from Anthropology and vice versa. Architectural Theory Review, 21(1), 27-43.

Till, J. (2008). Architecture and Contingency. 1(1), 120-135.

Till, J. (2009). Architecture Depends. London: MIT Press.

Van der Linden, V., Dong, H., \& Heylighen, A. (2018). Architects' Attitudes Towards Users:A Spectrum of Advocating and Envisioning Future Use(rs) in Design. Ardeth, (\#02), 197-216.

Verbeek, P. P. (2005). What things do: Philosophical reflections on technology, agency, and design (R. Crease, Trans.). University Park: Pennsylvania State university press.

Verhulst, L., Elsen, C., \& Heylighen, A. (2016). Whom do architects have in mind during design when users are absent? Observations from a design competition. Journal of Design Research, 14(4), 368-387.

Yaneva, A. (2009a). Making the Social Hold: Towards an Actor-Network Theory of Design. Design and Culture, 1(3), 273-288.

Yaneva, A. (2009b). The making of a building: A pragmatist approach to architecture. Oxford: Peter Lang.

Yaneva, A. (2012). Mapping controversies in architecture. Burlington: Ashgate. 


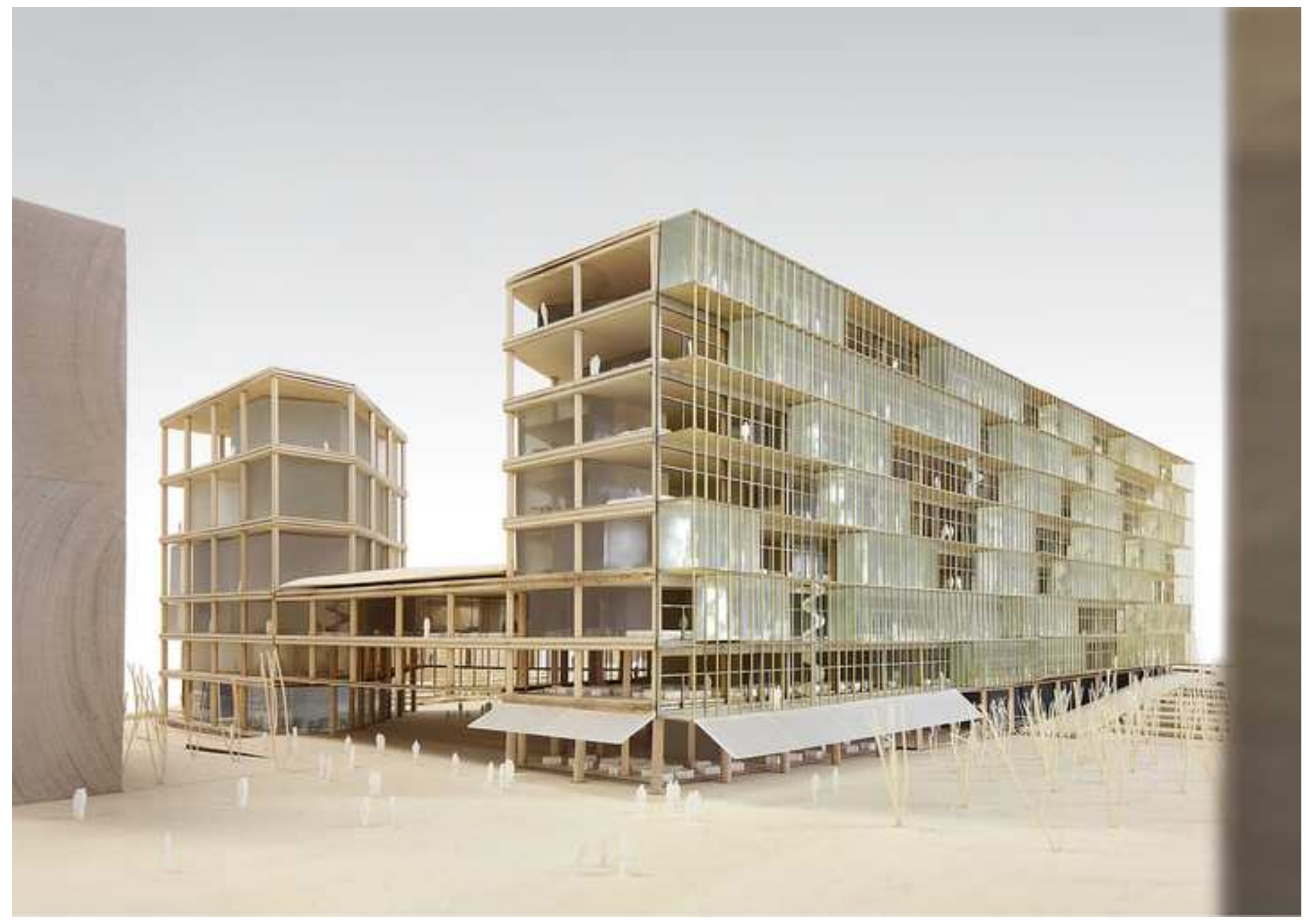




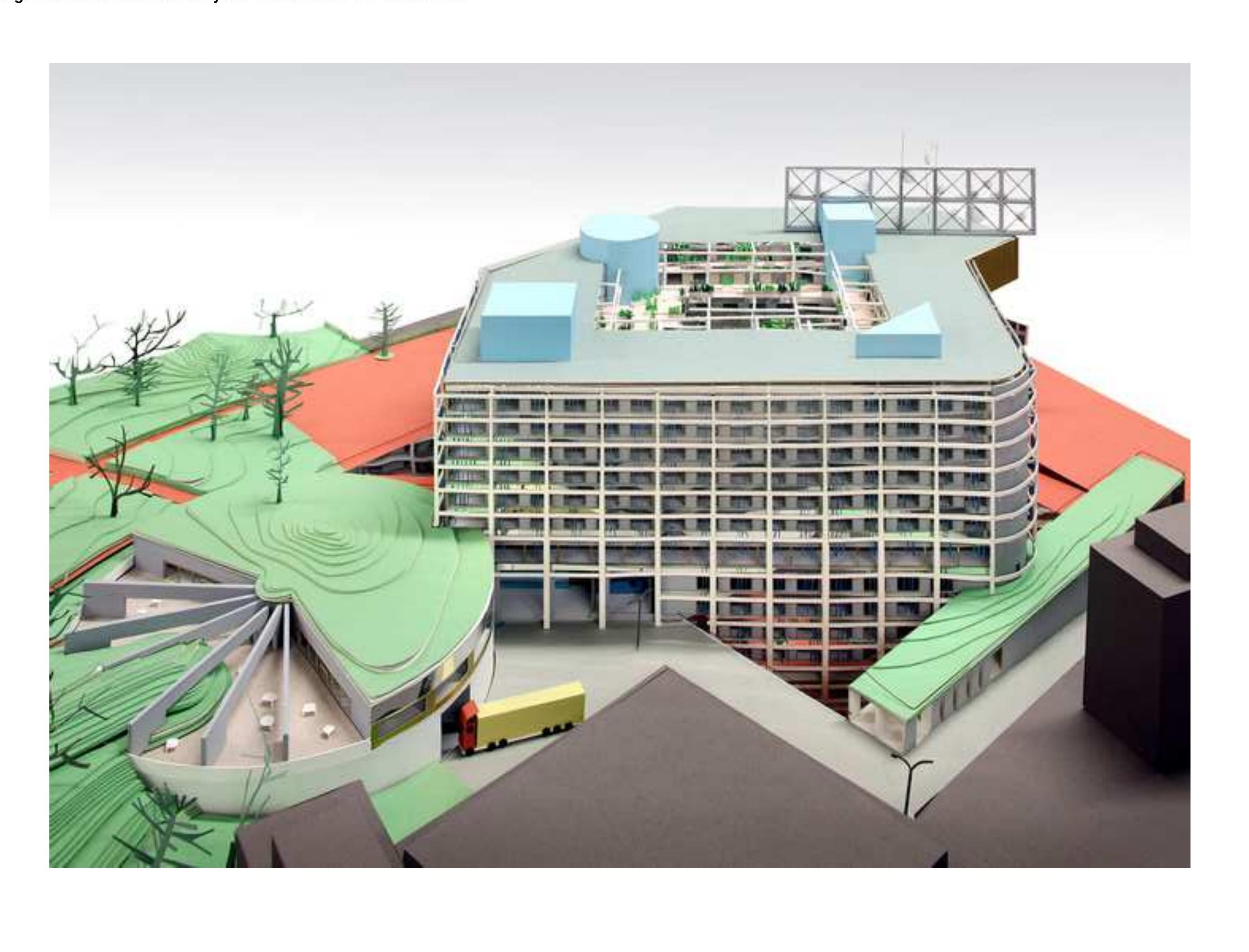

.

.

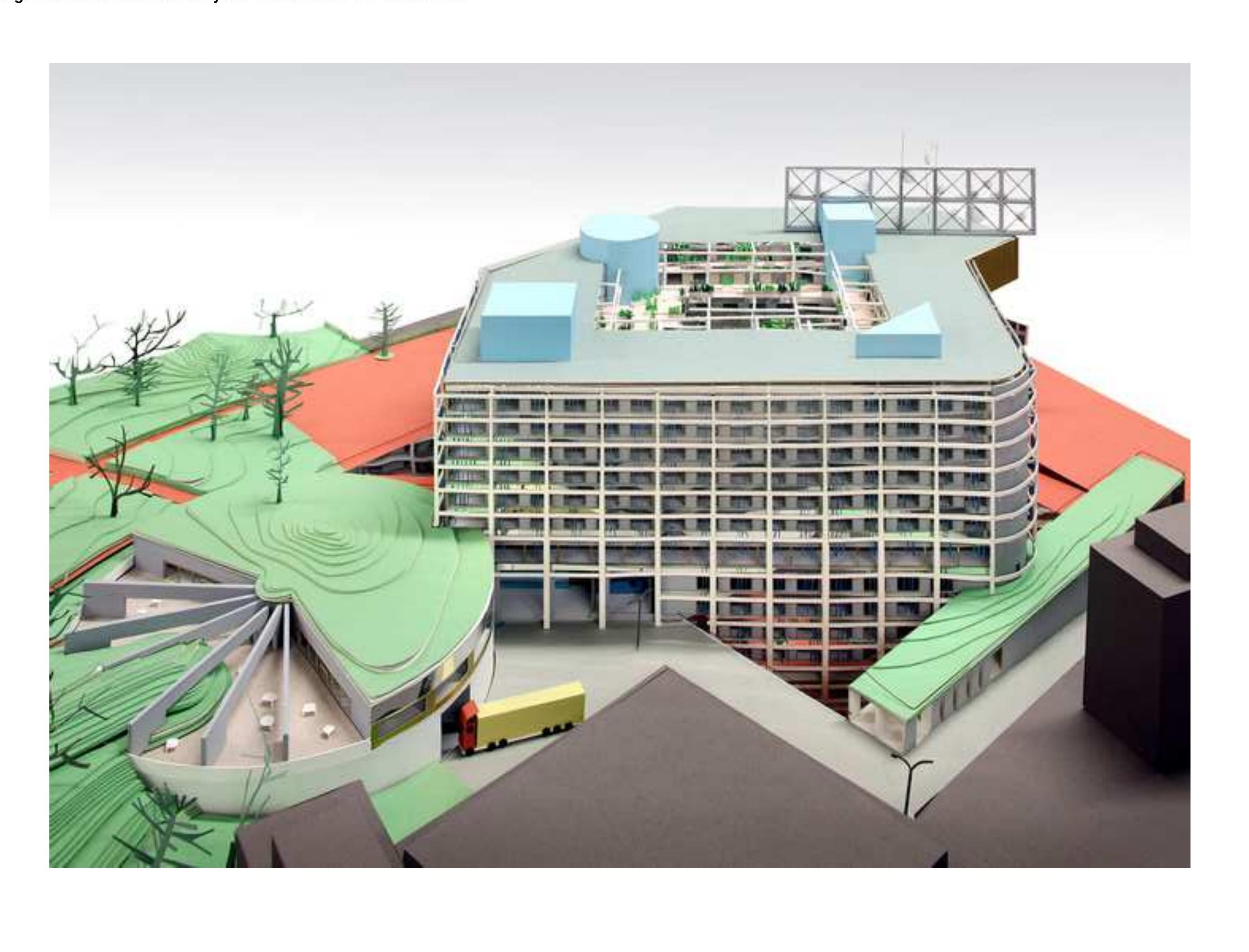




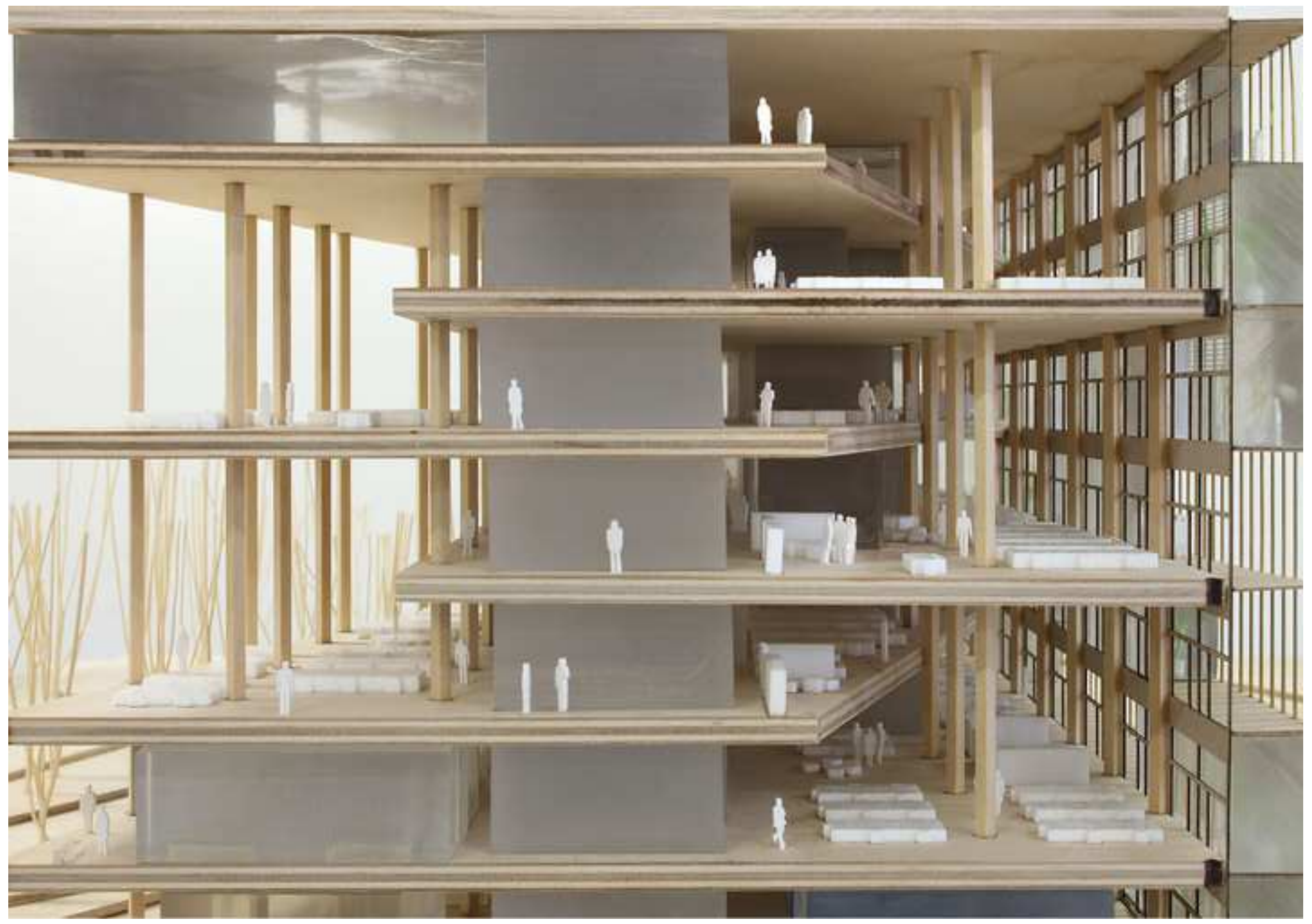




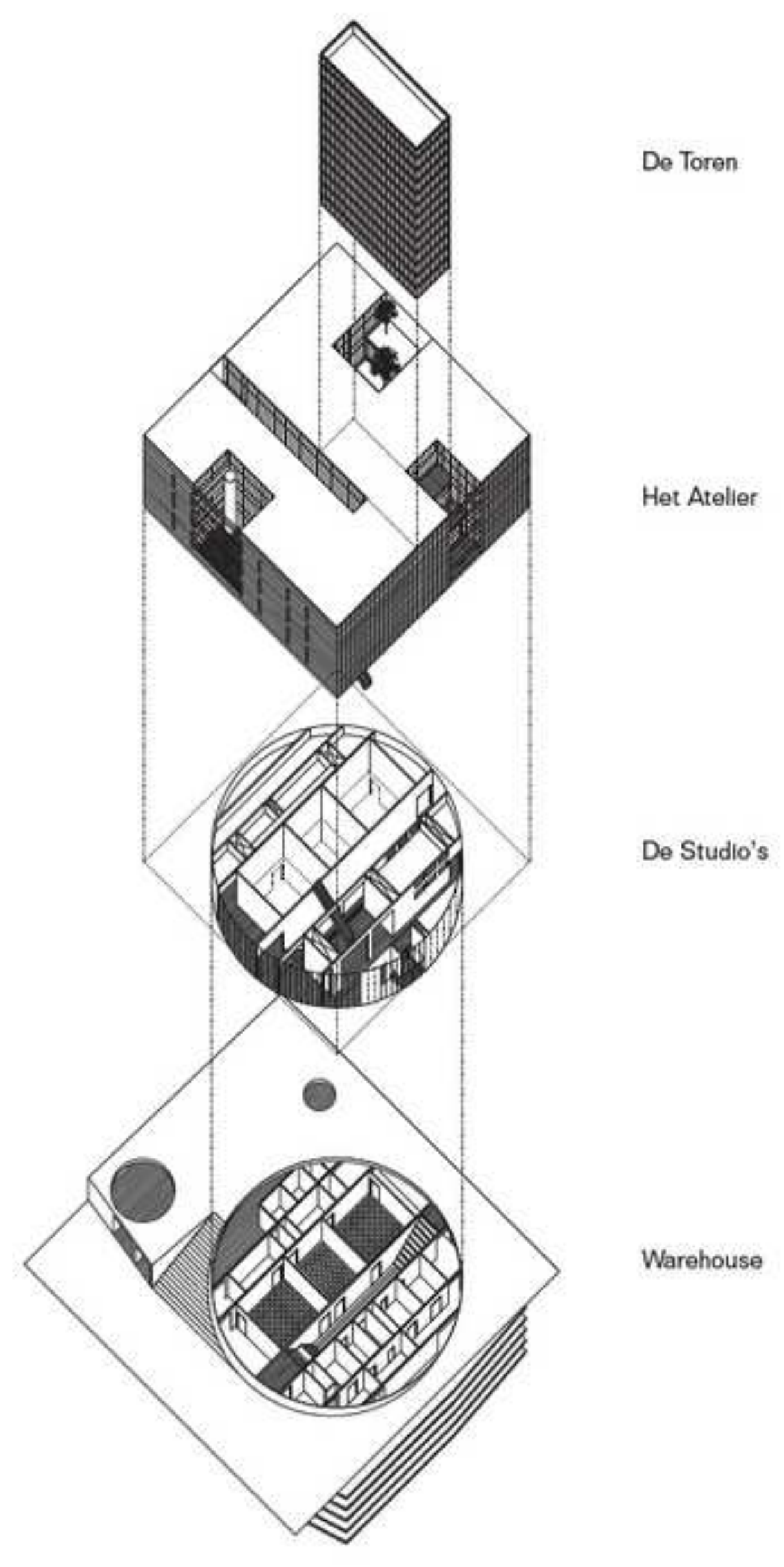

Fig.5. OFFICE's exploded view of volumes.

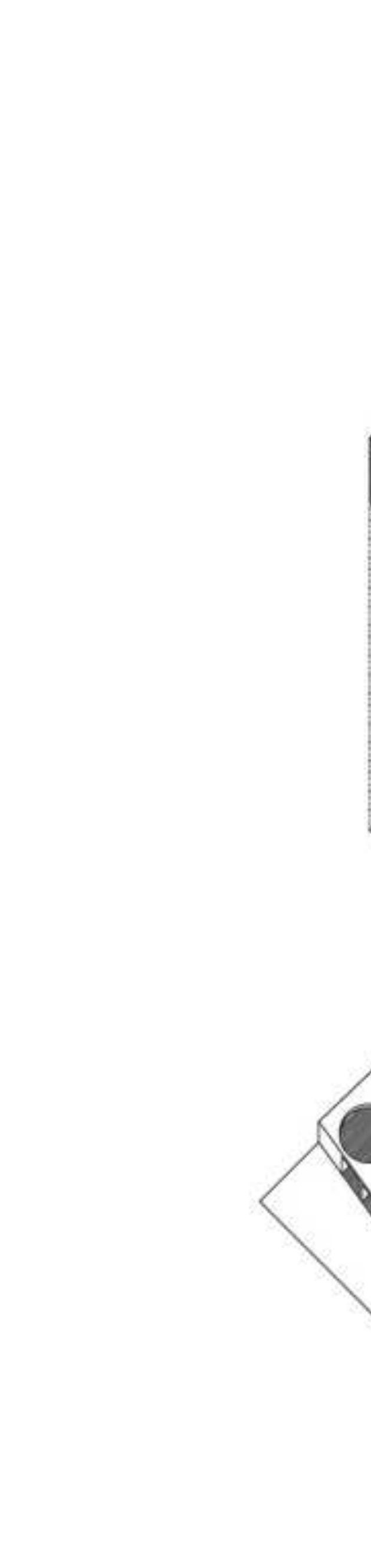

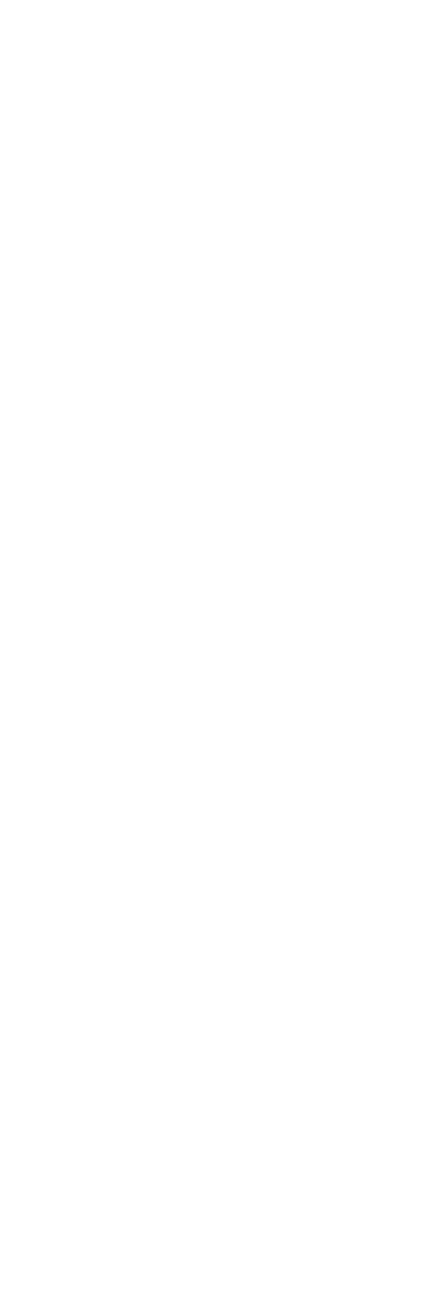

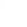

(1)

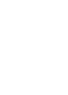

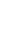



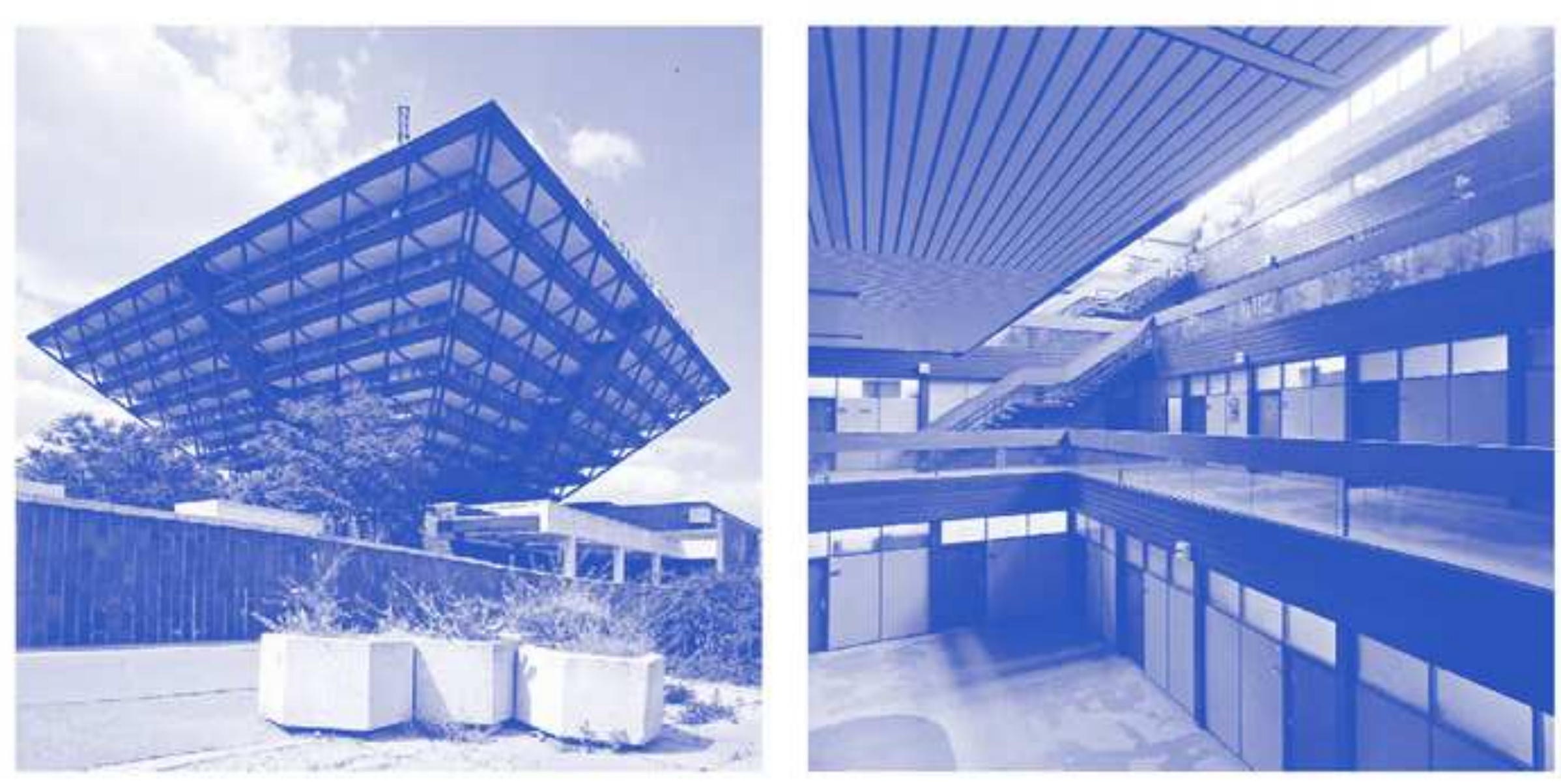